\title{
O imperativo do afeto na educação infantil: a ordem do discurso de pedagogas em formação
}

Rodrigo Saballa de Carvalho

\section{Resumo}

Este artigo apresenta resultados de uma pesquisa que teve como foco de análise a problematização dos discursos sobre afeto docente presentes em relatórios de um estágio realizado em turmas de Educação Infantil por 30 acadêmicas de pedagogia em fase de conclusão do curso. 0 objetivo do artigo é problematizar como os discursos sobre afeto se constituem enquanto imperativos que inventam e regulam os modos de exercício docente. 0 campo de estudos no qual se fundamentou a pesquisa foi o dos estudos culturais e dos estudos desenvolvidos por Michel Foucault. A metodologia consistiu na análise do discurso foucaultiana, por meio da qual foram destacadas as regularidades e inflexões presentes nos relatórios. Estes foram escritos a partir de elementos recordatórios, como fotos, planejamentos e demais registros das acadêmicas. A análise evidenciou a assunção da afetividade como um imperativo profissional associado a um processo de generificação da docência. A partir da pesquisa, concluiu-se que os significados do afeto no exercício da docência só existem como resultados inacabados de processos que tratam de nomeá-lo e conformá-lo. Por essa razão, se for assumida a perspectiva de que os discursos que tomam o afeto como imperativo docente presentes nos relatórios analisados são produzidos pelas práticas sociais, pelas relações de poder e pelo tipo de lógica disciplinar que os operacionaliza, é possível desnaturalizá-los e reinventá-los, experimentando outros modos de agir e de pensar o exercício da docência na Educação Infantil.

\section{Palavras-chave}

Educação Infantil - Afetos docentes - Discurso - Pedagogia.

I- Universidade Federal da Fronteira 


\title{
The imperative of affect in early childhood education: the order of discourse of undergraduate education students
}

Rodrigo Saballa de Carvalho'

\begin{abstract}
This article presents the results of a study that focused on the problematization of the discourses on teacher affect present in reports of an internship in early childhood education classes of 30 Education students nearing graduation. The aim of this paper is to discuss how discourses on affect become imperatives that invent and regulate the ways of teaching. The research was based on cultural studies and the studies developed by Michel Foucault. Its methodology consisted of Foucauldian discourse analysis, through which regularities and inflections found in the reports were highlighted. These reports were written using memory aids such as photos, plans, and other records of the students. The analysis evidenced the assumption of affection as a professional imperative associated with a process of gendering of teaching. From the research, it was concluded that the meanings of affect in the teaching profession only exist as unfinished results of processes that deal with naming it and shaping it. For this reason, if one assumes the perspective that the discourses that take affect as a teacher imperative, as the ones present in the reports analyzed, are produced by social practices, by the relations of power and type of disciplinary logic that operationalizes such discourses, it is possible to denaturalize them and reinvent them, experimenting with other ways of acting and thinking of teaching in early childhood education.
\end{abstract}

\section{Keyword}

Early Childhood Education - Teacher affect - Discourse - Pedagogy.

I- Universidade Federal da 


\section{Considerações iniciais}

Contemporaneamente, é possível observar que os discursos sobre a importância do afeto no processo educativo e da responsabilidade docente pela promoção de vínculos cada vez mais estreitos e duradouros com as crianças se proliferam nas searas educativas, conforme destaca Alves (2006). A questão afetiva e a linguagem sentimental, de acordo com Illouz (2011), ocupam um espaço singular e vêm adquirindo cada vez mais centralidade na descrição do cotidiano escolar. A afetividade do professor é muitas vezes entendida como o único atributo necessário para o exercício da docência. Vivencia-se uma espécie de inflação retórica de discursos sobre o afeto docente pelas crianças como estratégia infalível para a identificação e a resolução dos problemas em sala de aula.

A proliferação dos discursos afetivos, conforme aborda Abramowski (2010), iniciou-se a partir da circulação e da legitimação científica dos estudos advindos das pedagogias psicológicas; da comprovação, pelos especialistas em educação, da suposta falta de afeto das famílias em relação às crianças; dos estereótipos emocionais que constituem a definição e a normatização do perfil esperado de uma boa professora de Educação Infantil; e do crescente processo de afetivização da cena contemporânea, por meio da circulação, cada vez maior, de reality shows, livros de autoajuda, programas de entrevistas, entre outras pedagogias culturais que operam na subjetivação docente.

Desse modo, o presente artigo apresenta resultados de uma pesquisa que teve como foco a problematização dos discursos presentes em relatórios de práticas de estágio realizadas em turmas de Educação Infantil por acadêmicas de pedagogia em fase de conclusão do curso. 0 campo de estudos no qual se fundamentaram as análises desenvolvidas foi o dos estudos culturais e dos estudos desenvolvidos por Michel Foucault.

A metodologia utilizada consistiu na análise do discurso de inspiração foucaultiana, por meio da qual foram destacadas as regularidades e inflexões presentes nos discursos que constavam nos relatórios de estágio (referentes ao ano de 2011) das 30 participantes da pesquisa. Os relatórios tinham em média 60 páginas e apresentavam a seguinte estrutura: a) descrição da instituição; b) apresentação do projeto de intervenção; c) planejamentos semanais; d) relatos reflexivos escritos a partir das práticas desenvolvidas em sala de aula. 0 foco de análise foi somente os relatos reflexivos, escritos pelas acadêmicas com base em elementos recordatórios, como fotos, anotações e planejamentos. Com a análise dos dados, foi possivel notar a presença do imperativo do afeto nos discursos de todos os relatos, configurando determinadas funções enunciativas e produzindo regimes de verdade sobre a docência.

Tendo em vista visibilizar os discursos das acadêmicas sobre a importância do afeto e evidenciar que eles se valem de um vocabulário comum e de certas formas de argumentar, foram selecionadas para análise citações literais de trechos dos relatos reflexivos. Tais citações foram escolhidas pelo fato de apresentarem recorrentemente discursos relacionados ao afeto no exercício da prática docente. Após a seleção, os discursos foram organizados em unidades analíticas: afetos docentes, afetos considerados politicamente incorretos, mandatos pedagógicos afetivos e generificação dos afetos. No intuito de manter o anonimato das participantes, estas foram nomeadas pela letra A (acadêmica), seguida pela numeração correspondente de 01 a 30, ao final de cada citação. Sobre a instituição em que foi realizada a pesquisa, por solicitação, seu nome será mantido em sigilo. A partir da exposição da metodologia, cabe reiterar que, nos discursos analisados, evidenciou-se a assunção da afetividade como um imperativo profissional associado a uma generificação da docência.

$\mathrm{Na}$ contramão de tais discursos, entendendo gênero, segundo Scott (1995), Nicholson (2000) e Meyer (2003), como uma construção social culturalmente contingente e não como uma mera concretização de distinção biológica prévia, é possível dizer que as práticas 
sociais são constituídas e constituintes de gênero. Por essa razão, os significados do afeto no exercício da docência só existem como resultados inacabados de processos que tratam de nomeá-lo e conformá-lo. Desse modo, reconhecer-se como mulher e professora de Educação Infantil é decorrência de inúmeros processos educativos. 0 intuito do artigo é, assim, problematizar como os discursos sobre afeto presentes nos relatórios se constituem enquanto imperativos que inventam e regulam os modos de exercício profissional das futuras pedagogas. Nessa perspectiva, o imperativo do afeto pode ser descrito como o conjunto de discursos circulantes no meio social que operam na formação de uma profissional que entende o afeto (de modo naturalizado) como condição exclusiva para o exercício da docência com crianças, deixando em segundo plano (ou até mesmo desconsiderando) a formação acadêmica específıca para a atuação em sala de aula e os conhecimentos decorrentes de pesquisas produzidas na área. Esse imperativo está implicado no ordenamento da sala de aula e na autorregulação do trabalho docente, funcionando dentro de um sistema de produção e regulação de enunciados que define seu estatuto de verdade.

0 processo de afetivização da docência também se relaciona com os estereótipos emocionais definidores das características de uma boa professora de crianças. Conforme Abramowski (2010, p. 21), esses estereótipos prescrevem que "uma boa professora deve ter vocação pela sua tarefa e ser afetiva, meiga, simpática, carinhosa, compreensiva com as crianças". Tais enunciados evidenciam a importância concedida ao componente afetivo como condição imprescindível para o exercício da docência. A partir dessa lógica, o afeto pelas crianças é entendido de modo naturalizado, sendo suprimido seu caráter histórico e cultural. É como se o afeto pelas crianças fosse o único motivo para a escolha profissional, desconsiderando-se completamente o interesse acadêmico na área.
Alves (2006), em pesquisa realizada com pedagogas atuantes na Educação Infantil sobre o perfil profissional do educador da infância, destacou que as entrevistadas argumentavam que o trabalho que desenvolviam em sala de aula requeria prioritariamente amor às crianças e à profissão. 0 afeto era entendido como meio desencadeador de outras atitudes profissionais, como abertura a mudanças, compromisso, dedicação e responsabilidade. Em relação aos indicadores que, hipoteticamente, caracterizariam uma boa professora, as docentes elencaram simpatia, carinho, paciência, criatividade, tranquilidade, delicadeza, sutileza e capacidade de acolhimento às crianças, atribuindo, novamente, centralidade ao afeto no exercício qualificado da docência com crianças.

Com base na exposição, cabe esclarecer os demais conceitos que serão utilizados como ferramentas analíticas. Entendendo a partir de Foucault $(1995,2007)$ a centralidade da linguagem e da cultura na constituição dos sujeitos, podese dizer que os relatórios que compõem o corpus analítico da pesquisa serão examinados como discursos que procuram instituir e fixar determinados modos de exercício da docência na Educação Infantil. 0 discurso, em uma perspectiva foucaultiana, é considerado como mais do que uma simples representação, porque a linguagem é entendida como subsidiadora das categorias pelas quais os indivíduos nomeiam e agem no mundo, sendo, portanto, produtora de sentidos e significados que não preexistem às práticas discursivas. 0 discurso é concebido como uma prática (ou, ainda, um conjunto de práticas) que define e produz os objetos dos quais trata. Os relatórios dos estágios são vistos, nesse âmbito, como discursos que assumem forma, ordem e coerência por meio de uma linguagem comum, que opera sempre de modo microfísico, sutil, retórico e persuasivo, atualizando-se por meio de um sistema de remissões. Isso quer dizer que tais discursos são decorrentes de múltiplas combinações, interdições e atravessamentos de outros ditos, que os inscrevem em determinada ordem. 
Os significados a respeito do afeto no exercício da docência presentes nos escritos analisados não existem independentemente da ordem discursiva em que se encontram inscritos. Os registros evidenciam a presença de múltiplas vozes. Em todos os discursos enunciados nos relatórios, existem outras vozes a quem as acadêmicas se dirigem, outras vozes a quem se referem, outras vozes que falam em seus escritos. Em relação à consideração exposta, Arfuch (2010, p. 184) a ratifica, declarando que sempre há outras vozes que habitam os discursos - "a da tradição, da cultura, do senso comum: valorações, crenças, verdades aceitas que são assumidas como próprias, nas quais se imprime o selo afetivo". Reiterando o argumento apresentado, Foucault (1995, p. 8-9) afırma que a produção dos discursos: “ é ao mesmo tempo controlada, selecionada, organizada e redistribuída por certo número de procedimentos que tem por função conjurar seus poderes e perigos, dominar seu acontecimento aleatório" e afastar sua pesada e terrível materialidade.

A partir de sua circulação, os discursos promovem e instituem sentidos no social que incidem diretamente no processo de constituição dos indivíduos enquanto docentes e em suas concepções sobre a profissão. Nesse âmbito, as acadêmicas posicionam-se e são posicionadas no interior de certas regras, por meio das quais podem vir a conduzir os outros e a si mesmas, partindo do que estabelecem como sendo o exercício adequado da docência e o perfil da boa professora de Educação Infantil. Ao definirem o imperativo do afeto como o modo correto de ser e de agir com as crianças, as acadêmicas determinam um campo possível para suas ações e formas de ser enquanto professoras.

No intuito de visibilizar as estratégias discursivas presentes nos relatórios, na próxima seção serão apresentadas as análises referentes à temática dos afetos docentes.

\section{Afetos docentes}

É importante esclarecer que as discussões a serem expostas não tratam da oposição entre ser ou não um professor afetivo com as crianças, mas focalizam a primazia dos discursos sobre a afetividade no exercício da docência na Educação Infantil. Os discursos sobre afeto docente enunciados na pesquisa se relacionam com uma ampla rede discursiva histórica e cultural que posiciona as acadêmicas dentro de um regime de verdade em que ser afetiva é condição para o alcance do reconhecimento e da realização profissional. Esse regime de verdade institui o imperativo do afeto como condição exclusiva para o exercício profissional, operacionalizando um processo de subjetivação da acadêmica. Por meio de um autoexame contínuo, a acadêmica é produzida (e se produz), transformando suas maneiras de ser e de agir em relação ao trabalho e a si própria com vistas a tornar-se afetiva, como pode ser notado no excerto do relatório apresentado a seguir.

Durante minha prática de estágio na Educação Infantil, tive ainda mais certeza de que precisamos amar nossas crianças para ensinar, respeitando suas especificidades. A aprendizagem é uma consequência do carinho que demonstramos por elas. Através da convivência, acabamos gostando até das crianças mais terriveis, pois temos que aprender a lidar com todas sem exceção. Não é tarefa fácil, mas quem disse que é fácil ser professora? É uma diversidade enorme dentro da sala de aula e por isso é importante sabermos lidar de modo afetivo com todas as crianças para que todas possam aprender. (Transcrição de excerto de relatório de estágio A16).

Pelo exposto, é possível observar o modo como a acadêmica regula seu próprio discurso a partir da rede de práticas na qual se encontra inscrita, como jovem, branca, mulher, trabalhadora etc. Lidar com todas as crianças é um aprendizado e se constitui um desafio para quem assume a docência - pois quem disse que é fácil ser professora? É preciso aprender a lidar com a diversidade de crianças para que todas possam aprender. 
Ratificando a análise desenvolvida, é importante destacar o dito por Foucault (2005, p. 35), que afirma: é "sempre possível dizer o verdadeiro no espaço de uma exterioridade selvagem, mas o indivíduo não se encontra no verdadeiro senão obedecendo as regras de uma polícia discursiva" reativada sempre em cada um dos discursos enunciados pelos indivíduos. Eis o imperativo do afeto fazendo-se presente nas considerações. $\mathrm{Na}$ contramão dos discursos pedagógicos de ordem moral que definem o afeto como algo natural, o estabelecimento de vínculos afetivos com as crianças é uma prática desenvolvida no interior da cultura (via escolarização, formação docente, exercício profissional, pedagogias culturais que instituem e fazem circular discursos generificados sobre a docência, a aprendizagem, o trabalho pedagógico etc.) e, portanto, contingente e sujeito a múltiplas significações pelos indivíduos. Isso quer dizer que não se nega a importância do afeto nos processos de ensino e de aprendizagem, mas apenas se problematiza a naturalidade dos modos como os vínculos estabelecidos entre docentes e crianças na Educação Infantil têm sido enunciados de forma naturalizada no meio social como atributos da ordem do coração.

Abramowski (2010, p. 33) destaca que "os afetos que os indivíduos sentem não ocorrem de modo natural, não brotam de dentro para fora, não nascem do coração e muito menos das entranhas" dos professores. Os afetos, em todas as suas variantes, não são puros, naturais, espontâneos, instintivos, universais, eternos, nem imutáveis. Portanto, pode-se depreender que eles são históricos, cambiantes, construídos e aprendidos diariamente nas relações estabelecidas pela professora no contexto da sala de aula, ao educar, cuidar e brincar com as crianças, respeitando-as como sujeitos de direitos e produtoras de culturas infantis.

Assumindo essa contingência dos afetos docentes, é oportuno explorar a origem etimológica da palavra afeto. Etimologicamente, tal vocábulo origina-se de afecção, que tem o sentido de ser afetado, sofrer uma ação, ser influenciado ou modificado por uma ação. Nessa perspectiva, os afetos podem ser conceituados como as formas pelas quais os professores sentem, percebem, agem e expressam seus sentimentos em relação às crianças e ao trabalho que desenvolvem.

Por essa razão, o conceito de afetos docentes, segundo Abramowski (2010), contempla uma variedade de sentimentos vivenciados pelo professor em seu fazer profissional. Nessas experiências, estão incluídos tanto os sentimentos de amor, carinho, atenção e dedicação, como os de cansaço, angústia, aflição e raiva. Os afetos docentes não se restringem somente ao amor - palavra enunciada repetidamente na pesquisa. Os afetos incluem também os sentimentos considerados politicamente incorretos, que geralmente são interditados na ordem do discurso docente, conforme afirma a referida autora. Nesse sentido, ser um professor que realiza a mediação da aprendizagem dos alunos a partir do estabelecimento de vínculos afetivos é muitas vezes considerado - no meio educacional - o único indicador de qualidade do ofício profissional. Irritação, decepção, cansaço, falta de paciência, tristeza, mau humor, entre outros sentimentos, são vistos como déficit de competência emocional e profissional do professor, que sozinho deve procurar a solução para o problema. É possível perceber uma regulação marcante dos discursos dos docentes em relação ao que sentem por seus alunos e sua profissão, já que eles se encontram no âmbito da ordem do discurso afetivo.

Com base nessa linha argumentativa, serão apresentados e discutidos, na próxima seção, os afetos considerados politicamente incorretos $^{1}$ e seus efeitos no processo de subjetivação docente.

1- Expressão utilizada por Abramowski (2010) quando se refere, em sua pesquisa, aos sentimentos geralmente interditados nos discursos dos professores (cansaço, angústia, insatisfação etc.) em relação ao trabalho docente com as crianças. 


\section{Afetos considerados politicamente incorretos}

0 professor é um indivíduo deste mundo e, como tal, encontra-se suscetível aos sentimentos de irritação, angústia, desespero, insatisfação, cansaço, entre outras tantas sensações que poderiam ser elencadas. Ele aprende a controlar o livre fluir de seus próprios sentimentos e estados de ânimo a partir de um longo processo de disciplinamento e correlato aprendizado de autogoverno, que se inicia na família e se estende pela escolarização e pelo convívio social nas demais instituições. Esse autogoverno é de suma importância para que ele possa lidar cotidianamente com as crianças, já que o trabalho na Educação Infantil, além de pedagógico, é também relacional.

0 que faz com que o professor se controle é o fato de que ele, conforme afirma Abramowski (2010, p. 63), "não tem via livre para sentir qualquer coisa”. Ao entrevistar professores argentinos que atuavam na escolarização inicial, a autora percebeu que eles apresentavam dificuldade para expressar os sentimentos politicamente incorretos que sentiam em relação aos alunos e à profissão. Ao tratarem de tais sentimentos, os respondentes da pesquisa enfatizavam que, mesmo não gostando de determinadas crianças ou de situações ocorridas na escola, tinham a obrigação de controlar as palavras, dominar os instintos e metabolizar a raiva, pois os maus sentimentos não deveriam ser expressos nem em reuniões com a equipe gestora das instituições.

Embora, nas entrevistas com os professores, esses sentimentos sejam muitas vezes regulados, controlados e até mesmo excluídos dos discursos por não condizerem com as expectativas sociais que historicamente se têm em relação ao professor da Educação Infantil, é consenso que eles existem. Porém, é preciso que esses sentimentos sejam enunciados e discutidos no âmbito da formação acadêmica e também no espaço de atuação profissional. Mediante um processo de reflexão com os pares, o profissional terá a possibilidade de evidenciar os fatores atuantes no processo de constituição de seu desgaste, buscando auxílio para a resolução dos problemas apresentados e para a construção de estratégias com vistas à qualificação das relações estabelecidas com as crianças.

Corroborando esse argumento, é relevante apresentar o excerto de um relatório em que a acadêmica enfatiza:

[...] aprendi a lidar com as minhas emoções, pois, muitas vezes, perdi o controle e, dessa forma, acabei errando com as crianças. Uma professora de Educação Infantil jamais deve perder a calma e a paciência. (Transcrição de excerto de relatório de estágio A24)

É possível perceber a regulação do discurso sobre o afeto por meio de técnicas de conhecimento e controle de si que influenciam diretamente o modo como a acadêmica enuncia o que sente. Por outro lado, ao entrar na ordem do discurso que sustenta o imperativo do afeto, ela acaba muitas vezes desenvolvendo os sentimentos de culpa e má consciência, por nem sempre conseguir atender de forma solitária a todas as demandas afetivas contemporaneamente apresentadas pelas instituições escolares. Pode-se dizer que esses sentimentos passam a perturbar, atormentar e angustiar a futura professora, tornando-a presa aos seus próprios pensamentos:

Por mais que eu tente, nem sempre consigo atender às demandas afetivas de todas as crianças, pois existem muitas demandas. Fico angustiada, pois sei que a base de tudo é o carinho. (Transcrição de excerto de relatório de estágio A28)

Segundo Foucault (2003), essas relações de poder, produtoras da culpa e da má consciência, não definem o que é a estagiária em sua interioridade, mas procuram normalizá-la, no sentido de que ela assuma, cada vez mais, o repertório de características que historicamente 
foi definido como parte de sua profissão. No limite, trata-se de relações de poder que circulam microfisicamente via uma rede de discursos variados por todo o tecido social, produzindo, assim, a figura da docente afetiva.

Prosseguindo a discussão, na próxima seção serão discutidos os mandatos afetivos e o processo de subjetivação docente por eles operado.

\section{Mandatos pedagógicos afetivos}

Apesar de ter observado durante meu estágio na Educação Infantil professores que não preparam aulas, não pesquisam e nem demonstram um mínimo de amor por seus alunos, acredito que a educação pode melhorar muito. É preciso ser um professor afetivo e dedicado para que realmente a mudança ocorra em sala de aula. (Transcrição de excerto de relatório de estágio A28)

Percebi durante a minha prática em sala de aula com as crianças da Educação Infantil o quanto minhas atitudes marcam meus alunos. Procuro ser cuidadosa em tudo que falo e afetuosa em todas as minhas ações em sala de aula. (Transcrição de excerto de relatório de estágio A12)

Como consequência dos excertos apresentados, o professor se tornou merecedor de toda uma ortopedia discursiva que o incita a enunciar repetidamente a importância do afeto em sua profissão. Assim, estabelecem-se, de forma vertiginosa, publicações, palestras, entrevistas, vídeos e cursos de formação continuada que prescrevem procedimentos eficazes para o professor de Educação Infantil atingir sucesso no ensino a partir da criação e da manutenção de laços afetivos com as crianças. Trata-se de um investimento estratégico que inclui o docente em processos correlatos de autoavaliação e autorreconhecimento, capturando-o e moldando-o de modo que ele se reconheça e seja reconhecido como um profissional afetivo, que, por ter amor $\dot{a}$ profissão, não precisa reivindicar melhores condições de trabalho e remuneração financeira.

Esse argumento é ratificado pelos estudos de Abramowski (2010, p. 166), que afırma que os professores, tanto na formação inicial quanto no decorrer de suas práticas, "são subsidiados por discursos que ensinam a ser afetivo", pois se aprende a gostar dos alunos por meio de um longo processo. A ordem do discurso afetivo docente não tem como função apenas disciplinar, normalizar e interditar, mas também tem o propósito de intensificar a relação que o professor estabelece consigo no intuito de promover transformações em sua subjetividade. Por essa razão, é importante destacar a afırmação de Garcia (2002, p. 31) de que o modo como o professor se vê e se pensa, "bem como procura moldar sua conduta, é produto de práticas sociais particulares".

A subjetividade do professor é objeto de poder, é produto de maquinações, de saberes e técnicas que o incluem ativamente em um campo de visibilidade, atribuindo-lhe certo padrão de comportamento. 0 professor afetivo é produzido por determinadas práticas que o incitam a se reconhecer, a falar sobre si mesmo e a se tomar sob sua própria responsabilidade em um processo de autoavaliação permanente. A subjetividade decorrente desse processo pode ser considerada antes uma norma do que um dado natural. Isso ocorre porque a docência na Educação Infantil se torna alvo de uma rede de discursos que explicam, detalham, objetivam, tornam visíveis e passíveis de enunciação determinadas formas de se experienciar o afeto pelas crianças. Como pode ser percebido, opera-se uma condução do comportamento docente que não se caracteriza pela imposição, pela repressão ou pela ação de uma autoridade externa, mas, sutilmente, pelo modo como a acadêmica procura direcionar suas ações, tomando como referência a rede de discursos na qual se encontra inscrita.

Gostei muito da prática realizada na Educação Infantil, pois me propiciou vivenciar a rotina de uma sala de aula e 
percebi que tenho paciência e carinho para lidar com as crianças. Soube me portar com certa desenvoltura e intimidade com os alunos, soube respeitar as especificidades de cada aluno. Acho que tenho condições de ser uma boa professora. (Transcrição de excerto de relatório de estágio A14)

Em relação a esse excerto, é importante destacar duas considerações analíticas. A primeira diz respeito ao acento eminentemente moral e prescritivo nele presente. A acadêmica precisa dizer a verdade acerca de si própria, confessar-se, examinar-se e reconhecer-se como uma professora afetiva. Ela precisa se afirmar enquanto profissional por meio do testemunho público de suas próprias ações. Para tanto, necessita definir indicadores avaliativos que sejam devidamente reconhecidos no âmbito educacional, indicadores relacionados ao campo afetivo, como paciência, carinho, desenvoltura, intimidade e respeito aos alunos, os quais possibilitam validar sua própria atuação docente e ratificar o sucesso das propostas desenvolvidas em sala de aula. Além da defınição de indicadores, ela precisa estabelecer certa hierarquia entre eles. Paciência e carinho assumem o primeiro plano, compondo, com os demais aspectos citados, um vocabulário. Esse processo de escrutínio do eu não é algo natural, mas um empreendimento produtivo no qual concorrem diferentes práticas sociais que tornam a docente (auto)governável e cada vez mais identificada com o imperativo do afeto.

Quanto à segunda consideração analítica, observa-se o evidente atravessamento operado pelos estudos da psicologia no discurso em questão quando a acadêmica afirma que, em sua prática, soube respeitar as especificidades de cada um de seus alunos. Destaca-se, assim, conforme os estudos de Burman (1998), a relevância concedida ao relacional como traço emergente das teorizações psicológicas. É evidente a importância das questões relacionais no que diz respeito ao processo de ensino e aprendizagem; porém, muitas vezes, com base em leituras superficiais dos estudos decorrentes da psicologia, as acadêmicas acabam esquecendo a intencionalidade pedagógica de suas práticas. Por essa razão, é importante que o afeto seja pensado no contexto do trabalho pedagógico, articulado com as relações de cuidado, educação e ludicidade que são estabelecidas com as crianças no espaço institucional.

Análises sobre práticas pedagógicas desenvolvidas por Bujes (2009) e Walkerdine (1998) acentuam o quanto professores e acadêmicos, a partir de entendimentos equivocados, têm percebido a pedagogia como uma psicologia aplicada. A psicologia, nesse caso, torna-se o centro de produção de verdade sobre o aluno e a docência. Isso não significa que a psicologia sirva a propósitos de manipulação dos professores e nem que esse campo possua um discurso considerado homogêneo. 0 que se tem evidenciado é o modo equivocado como, muitas vezes, as teorizações de tal campo são apropriadas pelas acadêmicas, partindo da enunciação de jargões que, em muitos casos, não se relacionam com o trabalho pedagógico efetivo em sala de aula. Ainda a esse respeito, destaca-se a seguinte transcrição de outro excerto:

Tentei ser lúdica, teórica e afetiva ao mesmo tempo. Gostei do desafıo e me diverti muito mais do que as crianças enquanto aprendi e descobri como ser professora de Educação Infantil. Vi na sala de aula uma troca muito grande de amizade e carinho. (Transcrição de excerto de relatório de estágio A20)

Como consequência das considerações e dos posicionamentos expressos nos relatórios apresentados, é importante acompanhar Abramowski (2010) quando argumenta que, anteriormente, apelava-se para a autoridade do professor; hoje, insiste-se cada vez mais em conhecer profundamente o aluno e em gerar vínculos afetivos estreitos e duradouros com ele, deixando em segundo plano a relação afetiva estabelecida no contexto de ensino. Pode-se dizer que é na produção da subjetividade 
docente que o governamento se operacionaliza, já que a autoridade pedagógica passa a ser fundamentada em leituras (muitas vezes) superficiais da psicologia enquanto campo do saber. Referido de outro modo, mais do que a aplicação dos saberes da psicologia, a formação docente torna-se o lugar de difusão desse saber, de forma fragmentada e frequentemente sem articulação com o trabalho desenvolvido.

Corroborando os argumentos, a seguir será apresentada uma sequência de excertos do material produzido em que as acadêmicas evidenciam a satisfação que sentem em terem seu trabalho recompensado pelo afeto demonstrado pelas crianças com as quais atuam.

Semana de observação da prática de Educação Infantil. Sexta-feira - último dia de observação em uma turma de 5 anos de idade. Turma com 22 alunos. Um aluno tem diagnóstico médico de problemas neurológicos. Percebo que ele precisa de ajuda. Pego uma cadeira e sento ao seu lado. Passo a tarde inteira auxiliando-o e, diferentemente dos outros dias, ele consegue realizar pela primeira vez todas as atividades. No final da aula, ele me desenha em seu caderno. Saio muito feliz e com muita vontade de voltar, pois percebi que estabeleci um laço afetivo com a criança. (Transcrição de excerto de relatório de estágio A05)

Entrei na sala do berçário no horário de descanso, quando estavam todos com seus bicos e cheirinhos, dormindo. Comecei a conversar com as educadoras sobre a rotina, para poder me situar quanto aos horários das crianças. Enquanto a conversa transcorria, uma das educadoras precisou ausentar-se da sala para ir ao banheiro. Ficamos eu e outra estagiária cobrindo as crianças que haviam chutado seus cobertores durante o sono. Ao terminarmos isso, sentamos em um sofá para retomarmos a conversa, quando uma menina acordou. A menina sentou-se em um colchão, abriu o sorriso mais encantador que já vi e simplesmente disse: “Oi!". Nesse momento, percebi que, mesmo que não fosse bem aceita pela equipe de educadoras, eu consegui conquistar instantaneamente o carinho de uma menina, que, após sorrir, se levantou, correu até mim e me abraçou. Logo em seguida, os bebês foram acordando pouco a pouco, pegando seus sapatinhos e trazendo para que eu os colocasse. A cada vez que terminava de calçá-los, cada um me agradecia com os melhores presentes: um sorriso encantador, um abraço apertado ou um beijinho. (Transcrição de excerto de relatório de estágio A26)

Como tenho um jeito meio moleca de ser, acho que isso faz com que as crianças criem vínculos afetivos comigo mais rapidamente. Já fui bruxa, gato, coelho, noiva de festa junina - e adoro isso, poder ser diferentes pessoas e ver a alegria estampada em cada rostinho. (Transcrição de excerto de relatório de estágio A01)

Como docente em formação, posso sentir, a partir das práticas realizadas, o carinho e a admiração por parte das crianças. Como é recompensador saber que elas procuram o meu abraço, minha atenção e que sou amada por elas. Sinto-me realizada em receber o amor das crianças. (Transcrição de excerto de relatório de estágio A17)

Na verdade, ser professora é algo que ainda não sei expressar em palavras, é algo que sinto, penso, desejo quando estou frente aos bebês do meu estágio, estejam eles sorrindo, chorando, dormindo ou comendo. É algo que acontece e só depois é que consigo, talvez, pensar sobre. 0 que sei é que fico muito contente quando percebo que os bebês retribuem através do afeto todo o empenho e dedicação que tenho com eles durante as horas que passamos juntos. (Transcrição de excerto de relatório de estágio A21) 
A leitura possibilita enfatizar que, no entendimento das acadêmicas, o envolvimento afetivo com as crianças, além de influenciar diretamente o processo de ensino e aprendizagem, também é motivo de satisfação para elas. Em tal situação, a professora que não estabelece vínculos afetivos (entendidos, nesse caso, como beijos, abraços e afagos) com as crianças não é reconhecida como uma profissional qualificada. Percebe-se, então, a eficácia da rede de discursos que sustenta o imperativo do afeto, operando na mobilização da subjetividade das professoras em formação. Em outras palavras, os discursos que sustentam e incitam a produção da professora afetiva, ao descrevê-la e reconhecê-la somente por esse valor, buscam modos de condução desta. Tomando como referência as discussões desenvolvidas, é possível observar um produtivo processo de subjetivação, no qual o docente, ao ser constituído como objeto do discurso afetivo relacionado ao ensino, passa a ser caracterizado, classificado e identificado a partir de um sistema de normas sociais moralizantes que procuram enquadrá-lo dentro de uma média ou como um desvio a ser devidamente corrigido.

A esse respeito, conforme declara Badinter (1985, p. 15-16), deve-se sempre lembrar que o afeto "no reino humano não é apenas uma norma - pois nele intervêm numerosos fatores [discursos de diferentes ordens]". 0 afeto, segundo a referida autora, é apenas um sentimento humano, incerto, frágil, imperfeito e constituído no âmbito da cultura e das relações estabelecidas entre os indivíduos, não estando inscrito em suas naturezas. É um sentimento que pode existir ou não, aparecer e desaparecer, pois não é inerente à docência na Educação Infantil, mas adicional a ela por ser uma profissão relacional. Portanto, o processo de subjetivação do docente afetivo é efeito de uma produtiva rede de discursos que, ao descreverem, analisarem e narrarem o professor enquanto objeto de saber, subjetivam-no.

Prosseguindo com essa discussão, na próxima seção será abordado o processo de generificação dos afetos.

\section{A generificação dos afetos}

Lembro-me bem: "se não se comportar vai para a creche"; "coitada, não tem onde deixar os filhos e teve que colocar na creche" - falas de minha avó materna. Uma bagagem que carreguei, uma verdade desconfiada. Será que é tão ruim assim? Questionava-me. $\mathrm{Na}$ primeira experiência como estagiária de Pedagogia, a coordenadora me perguntou: "Tu já és mãe?"; "Sim.”; "Ótimo, pois preciso para o estágio no berçário de alguém com experiência. As outras acadêmicas que vieram não eram mães. Somente uma mãe é capaz de cuidar bem de uma criança, pois entende realmente as suas necessidades de carinho, alimentação e higiene". Chego na sala e observo: quatro bebês nos berços, três nos carrinhos. Pensei: "Como minha avó falou!”. (Transcrição de excerto de relatório de estágio A30)

Badinter (1985, p. 9) afirma que a maternidade ainda hoje é um tema sagrado e que, por essa razão, "continua sendo difícil questionar o amor materno, já que a mãe permanece em nossas representações - identificada a Maria, símbolo do indefectível amor oblativo". Tomando como referência essas observações, é possível pensar nas relações que ainda são estabelecidas entre maternagem e docência na Educação Infantil, assim como nos efeitos desse processo na invenção, na circulação e na manutenção de mandatos pedagógicos afetivos. Ser mãe foi o único critério utilizado para a aceitação da estagiária em uma turma de berçário, conforme consta no excerto.

É consenso que o trabalho com as crianças que se encontram na Educação Infantil (e também com as demais) envolve afeto, cuidado e educação (quanto aos aspectos relacionais de escuta, diálogo, atenção, respeito e acolhida); todavia, ser mãe não pode ser considerado critério indefectível para a definição da turma de uma estagiária, já que a maternagem, aliada ao 
propósito educativo, pode ser realizada independentemente de o profissional ser homem ou mulher, ter ou não filhos. 0 que é necessário é que essa pessoa esteja disposta a atender às demandas referentes à faixa etária das crianças com quem atua, tendo conhecimento teórico e empatia com o trabalho que realiza.

A diferença fundamental é que a maternagem exercida por um profissional de Educação Infantil deve estar associada a um projeto educativo que lhe possibilite refletir sobre as práticas por ele exercidas, tendo em vista a produção de sua própria docência sem se rotular com etiquetas de feminilidade, afetuosidade, calma, paciência, subserviência, entre outros tantos vocábulos usados de modo excessivo nos discursos escolares. 0 campo da docência com crianças pequenas é profundamente atravessado pela generificação dos afetos e muitas vezes assumido pelas próprias professoras como um trabalho exclusivamente feminino. Conforme refere Carvalho (1999, p. 215), no momento em que "um homem ou uma mulher decidem ser professores, devem lidar de alguma forma com o fato de que a docência junto a crianças foi historicamente associada a um modelo de feminilidade", devido ao seu caráter relacional e por evocar as relações de cuidado no interior da família.

Tais discussões têm a intenção de destacar que a vinculação entre maternagem e docência, por seu caráter cultural e simbólico, vem historicamente produzindo uma concepção naturalizada da relação entre mulher eafetividade que incide diretamente no modo como o docente se reconhece (e é reconhecido) e se posiciona (e é posicionado) como profissional que ensina crianças na escola. É possível dizer que, na Educação Infantil, existe o estabelecimento de uma notável relação entre maternagem e docência. Especificamente no que concerne ao trabalho nesse nível de ensino, a relação entre maternagem e docência é ainda mais visível, devido ao grande número de mulheres atuando como professoras, funcionárias e gestoras das instituições, ao predomínio de modos femininos de relacionamento entre elas e às práticas de cuidado realizadas cotidianamente, utilizando objetos relacionados ao contexto doméstico, que ajudam a confırmar a existência de um espaço no qual estão presentes ações socialmente reconhecidas como femininas e domésticas.

A imagem modelar da professora naturalmente afetiva e materna ainda se encontra fortemente marcada pelo mito da maternidade da mulher como sendo instintivamente carinhosa, paciente, dedicada, perspicaz, dinâmica e educadora nata -, cujo papel é associado diretamente ao trabalho doméstico de organização do lar, cuidado e educação das crianças pequenas. Em suma, conforme Arce (2001, p. 182), nota-se que essa situação vem se repetindo historicamente, porque, "a todo o momento, tem-se reforçado a imagem da professora de crianças como sendo uma educadora nata, passiva, paciente, amorosa, dedicada" e guiada, exclusivamente, pela ordem do coração, em detrimento de sua formação profissional. Ratificando tais colocações, a seguir serão apresentados excertos de relatórios analisados nos quais as acadêmicas se identificam e se descrevem enquanto signatárias do imperativo materno-afetivo.

Eu sou uma professora paciente, amorosa, carinhosa, respeitosa, sempre pronta a parar tudo e escutar a fala de todos os meus alunos. Professora que encanta, que conta histórias, que faz caretas, que brinca. Professora que erra, mas assume seus erros e que, errando, também aprende. (Transcrição de excerto de relatório de estágio A02)

Disposta, interessada, afetuosa, paciente, engajada, respeitosa, sonhadora, realista, ouvinte, falante, observadora, participante e atenta - assim me vejo como professora. (Transcrição de excerto de relatório de estágio A11)

Pelas práticas que realizei em sala de aula, me vejo como uma professora que transmite afeto e emoção em todos os 
seus atos, respeitando a singularidade dos sentimentos demonstrados pelas crianças na sala de aula. (Transcrição de excerto de relatório de estágio A25)

Nos momentos em que estive até então atuando na Educação Infantil, sempre procurei ser afetuosa e conhecedora dos anseios e das necessidades das crianças. A partir do afeto e do conhecimento das necessidades delas, passei a atuar de forma coerente e respeitosa, buscando a valorização das contribuições de tudo que minha turma trazia para a sala de aula. (Transcrição de excerto de relatório de estágio A18)

Relacionar a teoria com uma prática sempre é a minha meta; porém, valorizo muito as questões afetivas em sala de aula, principalmente na Educação Infantil. (Transcrição de excerto de relatório de estágio A03)

Enquanto mudo diariamente, as crianças são as minhas principais interlocutoras, pois, com sensibilidade e flexibilidade, elas me possibilitam criar novas estratégias. Sou uma professora atenta, paciente e muito carinhosa com as crianças, pois o amor vem sempre em primeiro lugar na Educação Infantil. (Transcrição de excerto de relatório de estágio A23)

A leitura possibilita destacar a presença de uma regularidade discursiva em que é evidente uma listagem de características materno-afetivas com as quais se identificam e se descrevem as acadêmicas enquanto futuras professoras. Ao se descreverem como professoras afetivas, as acadêmicas estão falando com base em um regime de verdade imerso em regras de formações discursivas historicamente construídas. Não são indivíduos autônomos que se descrevem como afetivos, mas indivíduos que assumem determinada posição na ordem do discurso e, nessa ordem, submetem-se a certas regras.
Por sua vez, a tônica das regras decorrentes dos discursos em questão é a de que, para ensinar, é preciso conhecer e amar os alunos, respeitando as necessidades de todos. Abramowski (2010, p. 158) afirma que "os discursos da psicologia ditam aos que querem ser bons professores que eles devem estabelecer vínculos próximos e íntimos com seus alunos", conhecendo-os como pessoas individuais, pois uma boa pedagogia será necessariamente relacional. Na medida em que, cotidianamente, tais discursos se tornam visíveis e enunciáveis, as características elencadas pelas acadêmicas passam a constituir-se em práticas bastante concretas, que operam efetivamente em sua normalização.

As características da professora afetiva que foram apresentadas nos discursos como supostamente naturais, constitutivas e intrínsecas ao fazer profissional das acadêmicas são efeitos de aparatos discursivos e linguísticos que assim as constituíram. A acadêmica, futura professora afetiva, longe de se configurar como uma essência universal e atemporal, é aquilo que foi (e é) feito dela, já que sua descrição naturalizada coloca em segundo plano seu processo de fabricação. Em outras palavras, reconhecer-se e descrever-se como uma profissional afetiva implica cuidar do próprio eu, ajustar-se ao exterior, oferecer-se como um repertório de verdades que, ao serem aprendidas e progressivamente operacionalizadas, inventam uma professora com certo modo de ser e certa maneira visível de agir com as crianças que se encontram sob sua responsabilidade.

Segundo essa lógica, tomando como referência os discursos analisados, depreende-se que o docente afetivo se reconhece e se descreve a partir de um vocabulário comum, marcado pelo afeto (no sentido de carinho) que sente em relação aos alunos. 0 vocabulário com o qual as acadêmicas se descrevem faz parte do processo de sua subjetivação e incide no que elas são e no que podem se tornar enquanto profissionais que exercem a docência com crianças. Por outro lado, é preciso esclarecer que esse processo, por ser microfísico, não ocorre com todas as acadêmicas do mesmo modo, pois é organizado 
com base em práticas sociais constituídas em relações de desigualdade, de poder e de controle, sempre passiveis de resistência.

Os discursos que referendam e prescrevem a formação da professora afetiva decorrentes dos estudos da psicologia das relações humanas e de suas adaptações por meio de livros de autoajuda para docentes, conforme aponta Burman (1998), têm encontrado cada vez mais repercussão e adesão de acadêmicos e professores que estão atuando nas escolas. Como pôde ser observado no decorrer das análises, os discursos afetivos são constituídos por um regime de verdade no qual se intensifica o argumento de que, para ensinar, é preciso amar os alunos e que, para amálos, é necessário desenvolver determinadas competências vinculadas diretamente ao campo emocional.

Referendando tais assertivas, Abramowski (2010, p. 158) afirma que os professores por ela entrevistados destacaram "que atualmente um bom professor deve ter conhecimentos de psicologia, deve ser um profissional flexível, comunicativo, paciente, ouvinte, respeitoso, empático e tolerante com todos os seus alunos".

Em outras palavras, um bom profissional deve possuir competência emocional. Segundo Illouz (2011), a competência emocional, atualmente, é considerada moeda imprescindível para atuar nas instituições. A partir do desmantelamento das antigas regras institucionais, os profissionais devem apelar ao afeto para construírem vínculos que antes já vinham estruturados. Tomando como referência as observações da autora, o imperativo do afeto tem se transmutado contemporaneamente em competência emocional, que o trabalhador deve desenvolver por meio da condução de si mesmo a fim de ser considerado um indivíduo supostamente eficaz, produtivo e bem-sucedido.

\section{Considerações finais}

A rede de discursos que opera na produção da professora afetiva constitui um conjunto de práticas que indica as formas a partir das quais as acadêmicas devem direcionar e moldar a conduta de si e dos outros, conforme pode ser acompanhado no excerto a seguir:

Serei uma professora que abrirá muitas portas para que as crianças conheçam e descubram o mundo. Serei uma líder que compreenderá as crianças, que saberá ouvir e falar, que conhecerá seus alunos. Serei como a pastora de um rebanho de ovelhas, não para prendê-las ou limitálas, mas para orientá-las para que saiam, um dia, mundo afora e descubram seus próprios caminhos. Serei uma professora que saberá cuidar de forma afetiva e estimulante. Enfim, serei educadora e mestra. Terei mais que um emprego. Terei uma profissão que gratifica, apaixona, enlouquece, cansa, ensina, envolve e acima de tudo realiza. (Transcrição de excerto de relatório de estágio A14)

Líder, pastora, educadora e mestra enfim, uma professora modelar constituída pelos discursos afetivos. É preciso esclarecer, a partir de Foucault (2003), que não existe algo (ou alguém) que seja responsável pela produção e circulação dos discursos afetivos (ou de quaisquer outros), senão os próprios indivíduos, por meio dos ideais que elegem como verdades. Por essa razão, é profícuo que, desde a formação acadêmica, o imperativo do afeto possa ser desnaturalizado e que as futuras professoras percebam que os discursos afetivos por elas tomados como verdades indeléveis ao fazer docente não passam de construções datadas, de invenções, sendo passíveis de problematização. Por isso, é importante que as acadêmicas compreendam a possibilidade de problematização dos discursos que as constituem como profissionais que têm somente o afeto como recurso para o exercício docente, passando a identificar a rede discursiva (composta por configurações institucionais, relações de poder e lógicas disciplinares) propulsora do imperativo do afeto. 
Obviamente que as provocações propostas não são simples. Por outro lado, se for assumida a perspectiva de que os discursos presentes nos relatórios analisados são produzidos a partir de uma rede discursiva, é possível desnaturalizá-los, repensá-los, reinventá-los, experimentando outras posições de sujeito, outros modos de agir e de pensar enquanto docente na Educação Infantil.

Talvez assim se possa, como sugere Abramowski (2010, p. 168): sacudir os estereótipos emocionais, revisar os discursos que formam as maneiras docentes de amar, retirar os afetos da zona escondida e estritamente singular, para situá-los em um plano coletivo, social, cultural e histórico.

Enfim, será possivel perceber a docência na Educação Infantil para além da ordem dos discursos que prescrevem o imperativo do afeto.

\section{Referências}

ABRAMOWSKI, Ana. Maneras de querer: Ios afectos docentes en las relaciones pedagógicas. Buenos Aires: Paidós, 2010.

ALVES, Nancy Nonato de Lima. "Amor à profissão, dedicação e o resto se aprende": significados da docência em Educação Infantil na ambiguidade entre a vocação e a profissionalização. In: REUNIÃO ANUAL DA ANPED, 29., 2006, Caxambu. Anais eletrônicos... Rio de Janeiro: ANPEd, 2006. CD-ROM.

ARCE, Alessandra. Documentação oficial e o mito da educadora nata na Educação Infantil. Cadernos de Pesquisa, São Paulo, v. 2, n. 113, p. 167-184, jul./dez. 2001.

ARFUCH, Leonor. 0 espaço biográfico: dilemas da subjetividade contemporânea. Rio de Janeiro: EDUERJ, 2010. Tradução de Paloma Vidal.

BADINTER, Elisabeth. Um amor conquistado: 0 mito do amor materno. Rio de Janeiro: Nova Fronteira, 1985. Tradução de Waltensir Dutra.

BUJES, Maria Isabel Edelweiss. Manuais pedagógicos e formação docente: elos de poder/saber. Currículo sem Fronteiras, v. 9 , n. 1, p. 267-288, jan.jjun. 2009.

BURMAN, Érica. La desconstrucción de la psicología evolutiva. Madrid: Visor, 1998.

CARVALHO, Marília Pinto. No coração da sala de aula: gênero e trabalho docente nas séries iniciais. São Paulo: Xamã: FAPESP, 1999.

FOUCAULT, Michel. Microfísica do poder. Rio de Janeiro: Graal, 1995. Tradução de Roberto Machado.

Ditos e escritos IV: estratégia poder-saber. Rio de Janeiro: Forense Universitária, 2003. Tradução de Vera Lúcia Avellar Ribeiro.

A ordem do discurso. São Paulo: Loyola, 2005. Tradução de Laura Fraga de Almeida Sampaio.

A arqueologia do saber. Rio de Janeiro: Forense Universitária, 2007. Tradução de Luiz Felipe Baeta Neves.

GARCIA, Maria Manuela Alves. Pedagogias críticas e subjetivação: uma perspectiva foucaultiana. Rio de Janeiro: Vozes, 2002.

ILLOUZ, Eva. 0 amor nos tempos do capitalismo. Rio de Janeiro: Zahar, 2011. 
MEYER, Dagmar. Gênero e educação: teoria e prática. In: LOURO, Guacira Lopes; NECKEL, Jane Felipe; GOELLNNER, Silvana Vilodre (Orgs.). Corpo, gênero e sexualidade: um debate contemporâneo na educação. Petrópolis: Vozes, 2003. p. 9-27.

NICHOLSON, Linda. Interpretando o gênero. Estudos Feministas, Florianópolis, v. 8, n. 2, p. 9-42, 2000.

SCOTT, Joan. Gênero: uma categoria útil de análise histórica. Educação \& Realidade, Porto Alegre, v. 20, n. 2, p. 161-176, jul./ dez. 1995.

WALKERDINE, Valerie. Uma análise foucaultiana da pedagogia construtivista. In: SILVA, Tomaz Tadeu (Org.). Liberdades reguladas: a pedagogia construtivista e outras formas de governo do eu. Petrópolis: Vozes, 1998. p. 143-213.

Recebido em: 27.01.2013

Aprovado em: 20.05.2013

Rodrigo Saballa de Carvalho é doutor e mestre em Educação pela Universidade Federal do Rio Grande do Sul (UFRGS), docente do curso de Pedagogia da Universidade Federal da Fronteira Sul (UFFS) e líder do Grupo de Pesquisas em Educação, Culturas e Políticas Contemporâneas (UFFS - Erechim/RS). 